Leukotriene receptor antagonists in adult asthma

\title{
Leukotriene receptor antagonists as add-on therapy for adults with asthma
}

\section{N C Thomson, M Shepherd}

Assessment of the current evidence for the use of leukotriene receptor antagonists as add-on therapy at steps 3 and 4 of the guidelines for adults with moderate to severe asthma.

\section{CHALLENGES IN MODERATE AND SEVERE PERSISTENT ASTHMA}

Of the 3.5 million adults with asthma in the UK, the majority have mild disease that can be controlled by inhaled short acting $\beta_{2}$ agonists alone or in combination with low to moderate doses of an inhaled corticosteroid. Twenty per cent have more severe asthma and often, despite multiple drug treatments, these patients experience considerable morbidity including frequent exacerbations..$^{23}$ The healthcare costs for moderate and severe persistent asthma are often high due to hospital admissions, absence from work, and drug usage. ${ }^{45}$ Guidelines on asthma management acknowledge the difficulties in achieving good asthma control in patients with moderate to severe disease defined by minimal symptoms, no exacerbations, no limitation of physical activity, and normal lung function, standards which can be achieved more easily in those with mild asthma. ${ }^{67}$ The challenge for academia, the pharmaceutical industry, and those involved in clinical care is to achieve good asthma control for adults with moderate to severe persistent disease by improving current management and by developing new improved treatments. The leukotriene modifying drugs, however, are the only new class of drugs that have been licensed for the treatment of asthma over the last 20 years. In this editorial we assess recent clinical trials of leukotriene receptor antagonists used as add-on treatment for adult patients with chronic asthma inadequately controlled on inhaled corticosteroids.

\section{RECOMMENDATIONS FROM ASTHMA GUIDELINES}

Recommendations from both national and international guidelines on the use of leukotriene receptor antagonists are broadly similar. ${ }^{7-9}$ The new British guideline on the management of asthma ${ }^{7}$ is evidence-based, using well defined methodology ${ }^{10}$ to evaluate all relevant published papers up to the end of September 2001. At step 3, inhaled long acting $\beta_{2}$ agonists are the first choice add-on therapy to low or moderate dose inhaled corticosteroids (fig 1). Adding a leukotriene receptor antagonist represents a second line option. For patients at step 4 who remain inadequately controlled on these combinations of treatments, possible interventions include increasing the inhaled corticosteroid dose to $2000 \mu$ g daily or adding on a leukotriene receptor antagonist, a long acting oral $\beta$ agonist, or a sustained release theophylline. Unfortunately no clinical trials of the benefits and safety of combinations of add-on therapies exist to guide management. Two papers published in this month's Thorax provide new information about several issues relating to the use of leukotriene receptor antagonists as add-on therapy to inhaled corticosteroids in adult asthma. ${ }^{112}$

\section{LEUKOTRIENE RECEPTOR ANTAGONISTS AND ASTHMA EXACERBATIONS}

The clinical efficacy of pharmacological drugs for asthma depends on their ability to decrease symptoms, improve lung function, and reduce asthma exacerbations. ${ }^{7}$ The leukotriene receptor antagonist montelukast has been shown to improve symptoms and lung function ${ }^{13}$ and several short to medium term studies have reported modest inhaled corticosteroid sparing effects. ${ }^{14} 15$ The ability of montelukast to influence exacerbation rates in adults has not previously been assessed. The leukotriene receptor antagonist zafirlukast administered at an unlicensed dose of $80 \mathrm{mg}$ twice daily to patients with severe persistent asthma receiving high dose inhaled corticosteroids at a dose of $\geqslant 1200 \mu \mathrm{g}$ daily for 6 weeks reduced exacerbations, improved symptoms, lung function and reduced $\beta_{2}$ agonist usage. ${ }^{16}$ A Cochrane systematic review of published and unpublished randomised controlled trials identified up to 2001 concluded that there was insufficient evidence, using the rate of exacerbations of asthma requiring rescue systemic corticosteroids as the primary outcome measure, to support the use of leukotriene receptor antagonists as add-on therapy to inhaled corticosteroids compared with doubling the dose of inhaled corticosteroid. ${ }^{17}$

In this issue of Thorax Vaquerizo and colleagues $^{11}$ report the results of a 16week randomised controlled trial in 639 adults with asthma inadequately controlled on inhaled budesonide at doses ranging from $400 \mu \mathrm{g}$ to $1600 \mu \mathrm{g}$ daily. Patients were randomised to receive either montelukast $10 \mathrm{mg}$ or placebo and to continue on a constant dose of inhaled budesonide. The group receiving montelukast showed improvements in the primary end point (mild asthma exacerbation days) and in various secondary end points including symptom score, $\beta_{2}$ agonist use, and morning PEF. The results were independent of budesonide dose. This large well conducted study provides good evidence that the addition of a leukotriene receptor antagonist to low, moderate, and high doses of an inhaled corticosteroid reduces mild asthma exacerbations and improves other indices of asthma control. The efficacy of montelukast in reducing the rate of severe exacerbations was not addressed in this study.

Previous studies have found that the efficacy of leukotriene receptor antagonists is less than that of inhaled long acting $\beta_{2}$ agonists as an add-on treatment to inhaled corticosteroids when assessed by changes in symptoms and lung function. ${ }^{18}{ }^{19} \mathrm{~A}$ randomised trial of inhaled salmeterol in a dose of $50 \mu \mathrm{g}$ twice daily compared with zafirlukast in a dose of $20 \mathrm{mg}$ twice daily found that the long acting inhaled $\beta_{2}$ agonist was more effective in improving symptoms and lung function in adult patients with persistent asthma, the majority of whom were receiving inhaled corticosteroids. ${ }^{18}$ A 12-week comparison of fluticasone $200 \mu \mathrm{g}$ plus salmeterol $100 \mu \mathrm{g}$ daily with fluticasone $200 \mu \mathrm{g}$ plus montelukast $10 \mathrm{mg}$ daily $^{19}$ found that the former combination produced greater improvement in asthma control. A long term trial is indicated comparing the effectiveness of leukotriene receptor antagonists and inhaled long acting $\beta_{2}$ agonists alone and in combination as add-on therapy to low to moderate doses of inhaled corticosteroids, with asthma exacerbation rates as the primary outcome measure.

\section{LEUKOTRIENE RECEPTOR ANTAGONIST COMPARED WITH DOUBLING THE DOSE OF INHALED CORTICOSTEROID AS ADD-ON TO MODERATE DOSES OF INHALED CORTICOSTEROID}

For most patients with asthma a plateau in the therapeutic response to inhaled 


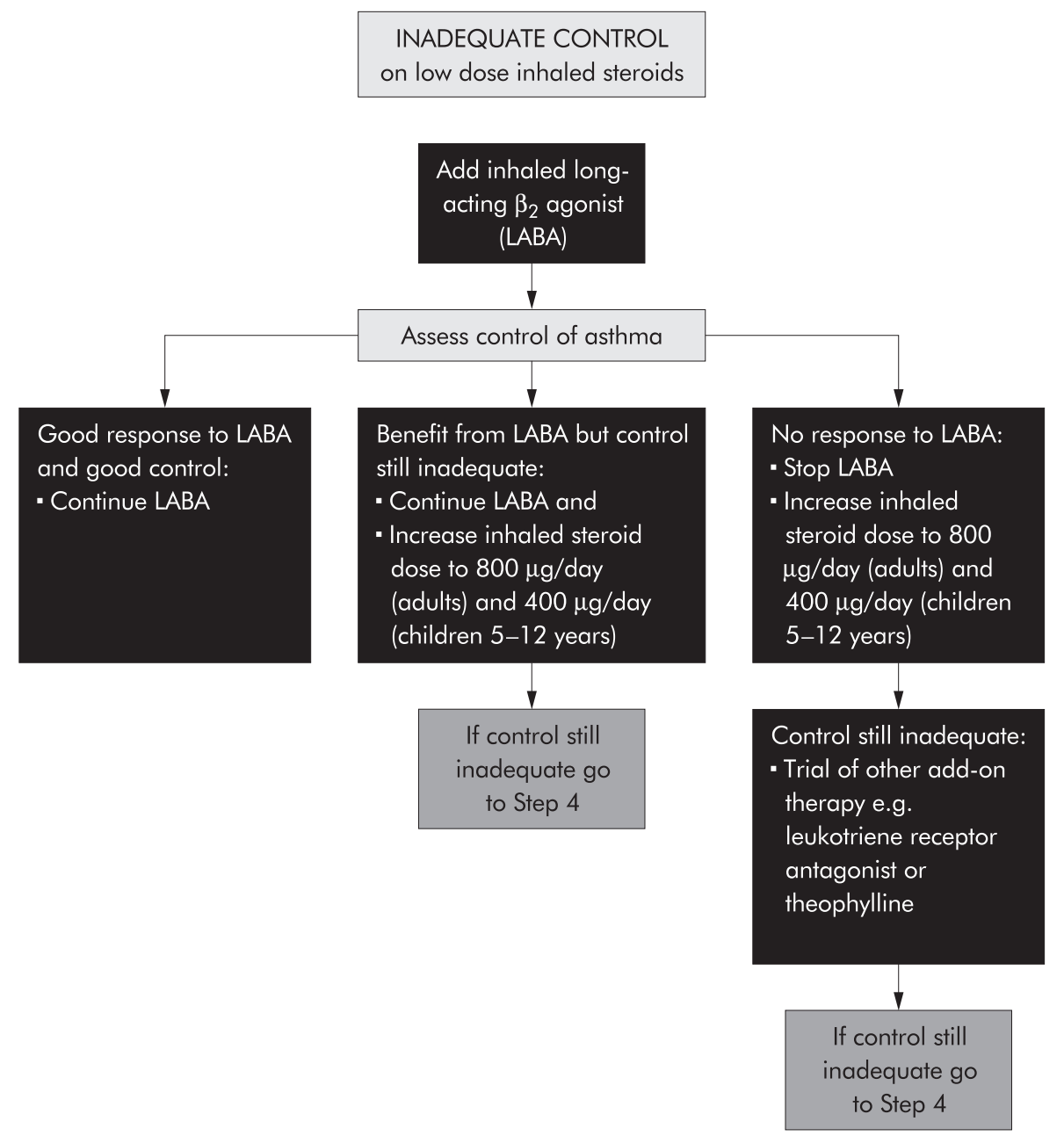

Figure 1 Step 3: Add-on therapy. Reproduced from BTS/SIGN.?

corticosteroids exists at doses below $1000 \mu \mathrm{g}$ inhaled beclomethasone or equivalent. ${ }^{20-23}$ Although some patients may obtain additional benefit from higher doses, the risk of systemic adverse effects starts to rise. In this issue of Thorax Price and colleagues ${ }^{12}$ report the results of a 16-week randomised controlled trial in 889 adults with asthma inadequately controlled on inhaled budesonide $800 \mu \mathrm{g}$ daily. Patients received either montelukast $10 \mathrm{mg}$ plus inhaled budesonide $800 \mu \mathrm{g}$ daily or inhaled budesonide $1600 \mu \mathrm{g}$ daily. Both groups had similar improvements in the primary end point (morning PEF) and in secondary end points including symptoms, exacerbations, and asthma specific quality of life. Adding montelukast led to a slightly faster onset of action and both drug regimes were well tolerated. This large study provides good evidence that the efficacy of adding a leukotriene receptor antagonist is similar to doubling the dose of inhaled corticosteroid. Potential criticisms are that the trial may not have been long enough to detect differences in exacerbation rates and the lack of a placebo group prevented an assessment of the magnitude of response to the active treatments. Many patients at step 4 who have asthma that is not adequately controlled on an inhaled corticosteroid at a dose of $800 \mu \mathrm{g}$ daily are receiving an inhaled long acting $\beta_{2}$ agonist, and it remains unclear whether the addition of a leukotriene receptor antagonist is of clinical benefit in this circumstance. In a group of 72 patients with symptomatic chronic persistent asthma already taking high dose inhaled corticosteroids and other add-on therapies such as a long acting inhaled $\beta_{2}$ agonist, the addition of montelukast for 2 weeks did not improve symptoms or PEF recordings, ${ }^{24}$ although the effect of long term treatment on exacerbation rate has not been examined. Leukotriene receptor antagonists might be less effective or ineffective in patients with moderate or severe asthma already receiving multiple drug therapies.

\section{SAFETY OF LEUKOTRIENE RECEPTOR ANTAGONISTS}

In clinical trials, including those reported in this issue of Thorax, ${ }^{11}{ }^{12}$ the leukotriene receptor antagonists montelukast and zafirlukast have been well tolerated. The main side effects reported were headache and gastrointestinal disturbance. Administration of the leukotriene receptor antagonists has been associated with the development of the Churg-Strauss syndrome but it seems unlikely that this is a causal relationship. $^{25} 26$

\section{PLACE OF LEUKOTRIENE RECEPTOR ANTAGONISTS AS ADD-ON THERAPY}

The most effective use of leukotriene receptor antagonists can be established only through clinical trials that recruit patients from the full spectrum of asthma severity. The studies on the use of leukotriene receptor antagonists as add-on therapies reported in this issue of Thorax may not be representative of the full range of adult asthmatics in the general population. For the purposes of regulatory submissions, pharmaceutical products are usually evaluated using randomised controlled clinical trials which inevitably are conducted in relatively small highly selected patient populations. These studies are efficient in that they provide an excellent context within which to evaluate the potential efficacy of the new product using a minimal 
number of patients, but do not provide adequate data on the implications of the introduction of the product into normal clinical practice, involving the treatment of the much more diverse patient population that exists in real life. Additional diversity comes from extremes of age, non-white populations, non-asthma drug treatment, and diseases in addition to asthma. Asthmatic patients may be smokers, and smoking has been associated with impaired efficacy of inhaled corticosteroids. ${ }^{27}$ In addition, nonpragmatic studies are ineffective for determining long term safety. ${ }^{28}$

Based on current published evidence, leukotriene receptor antagonists are second line alternatives to inhaled long acting $\beta_{2}$ agonists as add-on therapy at step 3 of the asthma guidelines. ${ }^{7}$ This recommendation might need to be reviewed following the outcome of long term studies comparing the two classes of drugs using a range of end point measurements including asthma exacerbation rate. For patients at steps 3 or 4 of the guidelines who are receiving an inhaled corticosteroid at a dose of at least $800 \mu \mathrm{g}$ daily but who are not taking an inhaled long acting $\beta_{2}$ agonist, the addition of a leukotriene receptor antagonist has been shown to be as beneficial as doubling the dose of inhaled corticosteroid, at least over the medium term. Future pragmatic clinical studies should examine the long term benefits and safety of different add-on therapies including leukotriene receptor antagonists to help guide the management of moderate to severe asthma.

Thorax 2003;58:190-192

\section{Authors' affiliations}

N C Thomson, M Shepherd, Department of Respiratory Medicine, Division of Immunology, Infection \& Inflammation, University of Glasgow \& Western Infirmary, Glasgow G1 1 6NT, UK
Correspondence to: Professor N C Thomson, Department of Respiratory Medicine, Division of Immunology, Infection \& Inflammation,

University of Glasgow \& Western Infirmary, Glasgow G1 1 6NT, UK

n.c.thomson@clinmed.gla.ac.uk

\section{REFERENCES}

1 Walsh L, Wong C, Cooper S, et al. Morbidity from asthma in relation to regular treatment: a community based study. Thorax 1999:54:296-300.

2 Rabe KF, Vermiere PA, Soriano JB, et al. Clinical management of asthma in 1999: the Asthma Insights and Reality in Europe (AIRE) study. Eur Respir J 2000; 16:802-7.

3 Strachan DP. Defining unmet need. Asthma J 2000:5: 137-40.

4 Hoskins G, McCowan C, Neville RG, et al. Risk factors and costs associated with an asthma attack. Thorax 2000;55: 19-24.

5 Serra-Batlles J, Plaza V, Morejon E, et al. Costs of asthma according to the degree of severity. Eur Respir J 1998;12:1322-6.

6 British Thoracic Society. The British guidelines on asthma management: 1995 review and position statement. Thorax 1997;52(Suppl 1):S1-21.

7 British Thoracic Society/Scottish Intercollegiate Guideline Network (BTS/SIGN). British guideline on the management of asthma. Thorax 2003;58(Suppl I):i1-94.

8 National Institutes of Health. Highlights of the Expert Panel Report II: Guidelines for the diagnosis and management of asthma. $\mathrm{NIH}$ publication no. 97-4051. Bethesda, MD: National Institutes of Health, 1997.

9 National Institutes of Health, National Heart, Lung and Blood Institute. Global initiative for asthma. Global strategy for asthma management and prevention. Publication no. 95-3659. Bethesda, MD NHLBI/WHO Workshop Report, 1995.

10 Scottish Intercollegiate Guideline Network (SIGN). SIGN 50: a guideline developer's handbook. SIGN publication no. 50 . Edinburgh: SIGN, 2002

11 Vaquerizo MJ, Casan P, Castillo J, et al. Effect of montelukast added to inhaled budesonide on control of mild to moderate asthma. Thorax 2003;58:204-10.

12 Price DB, Hernandez D, Magyar P, et al. Randomised controlled trial of montelukast plus inhaled budesonide versus double dose inhaled budesonide in adult patients with asthma. Thorax 2003;58:211-6.

13 Laviolette M, Malmström K, Lu S, et al. Montelukast added to inhaled beclomethasone in treatment of asthma. Am J Respir Crit Care Med 1999;160:1862-8.
14 Löfdahl C-G, Reiss TF, Leff JA, et al. Randomised, placebo controlled trial of effect of a leukotriene-receptor antagonist, montelukast, on tapering inhaled corticosteroids in asthmatic patients. BM 1999;319:87-90

15 Tohda $\mathrm{Y}$, Fujimuri $M$, Taniguchi $\mathrm{H}$, et al. Leukotriene receptor antagonist, montelukast, can reduce the need for inhaled steroid while maintaining the clinical stability of asthmatic patients. Clin Exp Allergy 2002;32:1 180-6.

16 Patients. Clin Exp Allergy 2002; 32 : Zafirlukast improves asthma control in patients receiving high-dose inhaled corticosteroids. Am J Respir Crit Care Med

2000;162:578-85

17 Ducharme F, Hicks G, Kakuma R. Addition of anti-leukotriene agents compared to inhaled corticosteroids for chronic asthma (Cochrane corticosteroids for chronic asthma (Cochran
Review). In: The Cochrane Library. Issue 1. Oxford: Update Software, 2002.

18 Busse W, Nelson H, Wolfe J, et al. Comparison of inhaled salmeterol and oral zafirlukast in patients with asthma. J Allergy Clin Immunol 1999; 103:1075-80.

19 Nelson HS, Busse WW, Kerwin E, et al. Fluticasone propionate/salmeterol combination provides more effective asthma control than low dose inhaled corticosteroid plus montelukast. J Allergy Clin Immunol. 2000; 106: 1088-95.

20 Gershman NH, Wong HH, Liu JT, et al. Low and high-dose fluticasone propionate in asthma: effects during and after treatment. Eur Respir J 2000;15:11-8.

21 Holt S, Suder A, Weatherall M, et al Dose-response relation of inhaled fluticasone propionate in adolescents and adults with asthma: meta-analysis. BM 2001;323:253-6.

22 Bousquet J, Ben-Joseph R, Messonnier M, et al. A meta-analysis of the dose-response relationship of inhaled corticosteroids in adolescents and adults with mild to moderate persistant asthma. Clin Ther 2002:24:1-20.

23 Adams N, Bestall J, Jones P. Inhaled beclomethasone at different doses for long term asthma (Cochrane Review). In: The Cochrane Library. Issue 1. Oxford: Update Software, 2001

24 Robinson DS, Campbell D, Barnes PJ. Addition of leukotriene antagonists to therapy in chronic persistent asthma: a randomised double-blind placebo-controlled trial. Lance 2001;357:1991-2.

25 Stirling RG, Chung KF. Leukotriene antagonists and Churg-Strauss syndrome: the smoking gun. Thorax 1999:54:865-6.

26 Tuggery JM, Hosker HSR. Churg-Strauss syndrome associated with montelukast therapy. Thorax 2000;55:805-6.

27 Chalmers GW, Macleod KJ, Little SA, et al. Influence of cigarette smoking on inhaled corticosteroid treatment in mild asthma. Thorax 2002;57:226-30.

28 Tattersfield AE, Harrison TW. Step 3 of the asthma guidelines. Thorax 1999;54:753-4. 